\title{
ALS is a multistep process in South Korean, Japanese, and Australian patients
}

Steve Vucic, DSc, Mana Higashihara, PhD, Gen Sobue, MD, Naoki Atsuta, MD, Yuriko Doi, MD, Satoshi Kuwabara, PhD, Seung Hyun Kim, MD, PhD, Inah Kim, MD, MPH, PhD, Ki-Wook Oh, MD, PhD, Jinseok Park, MD, PhD, Eun Mi Kim, MPH, Paul Talman, PhD, Parvathi Menon, PhD, and Matthew C. Kiernan, DSc, the PACTALS Consortium

Neurology ${ }^{\circledR}$ 2020;94:e1657-1663. doi:10.1212/WNL.0000000000009015

\section{Abstract \\ Objective}

To establish whether amyotrophic lateral sclerosis (ALS) is a multistep process in South Korean and Japanese populations when compared to Australian cohorts.

\section{Methods}

We generated incident data by age and sex for Japanese (collected between April 2009 and March 2010) and South Korean patients with ALS (collected between January 2011 and December 2015). Mortality rates were provided for Australian patients with ALS (collected between 2007 and 2016). We regressed the log of age-specific incidence against the log of age with least squares regression for each ALS population.

\section{Results}

We identified 11,834 cases of ALS from the 3 populations, including 6,524 Australian, 2,264 Japanese, and 3,049 South Korean ALS cases. We established a linear relation between the log incidence and log age in the 3 populations: Australia $r^{2}=0.99$, Japan $r^{2}=0.99$, South Korea $r^{2}$ $=0.99$. The estimate slopes were similar across the 3 populations, being 5.4 (95\% confidence interval [CI], 4.8-5.5) in Japanese, 5.4 (95\% CI, 5.2-5.7) in Australian, and 4.4 (95\% CI, 4.2-4.8) in South Korean patients.

\section{Conclusions}

The linear relationship between log age and log incidence is consistent with a multistage model of disease, with slope estimated suggesting that 6 steps were required in Japanese and Australian patients with ALS while 5 steps were needed in South Korean patients. Identification of these steps could identify novel therapeutic strategies.

\section{Correspondence}

Dr. Vucic

steve.vucic@sydney.edu.au

\section{MORE ONLINE}

\section{ค Podcast}

Dr. Matthew Harms talks with Dr. Steve Vucic about his paper on the multiple hit theory of ALS.

NPub.org/ekjide

From the Westmead Clinical School (S.V., M.H., P.M.), University of Sydney, Australia; Department of Neurology (N.A.), Nagoya University Graduate School of Medicine (G.S.); The National Institute of Public Health (Y.D.), Wako-shi; Chiba University Graduate School of Medicine (S.K.), Japan; Department of Neurology (S.H.K., K.-W.O., J.P.), Hanyang University Hospital; Department of Health Sciences (I.K., E.M.K.), Hanyang University Graduate School; Department of Occupational and Environmental Medicine (I.K.), College of Medicine, Hanyang University, Seoul, Republic of Korea; Geelong Hospital (P.T.); and Brain and Mind Centre (M.C.K.), University of Sydney and Institute of Clinical Neurosciences, Royal Prince Alfred Hospital, Sydney, Australia.

Go to Neurology.org/N for full disclosures. Funding information and disclosures deemed relevant by the authors, if any, are provided at the end of the article. 


\section{Glossary}

ALS = amyotrophic lateral sclerosis; $\mathbf{C I}=$ confidence interval; ICD-10 = International Classification of Diseases-10; IRB = institutional review board; PACTALS = Pan-Asian Consortium for Treatment and Research in ALS.

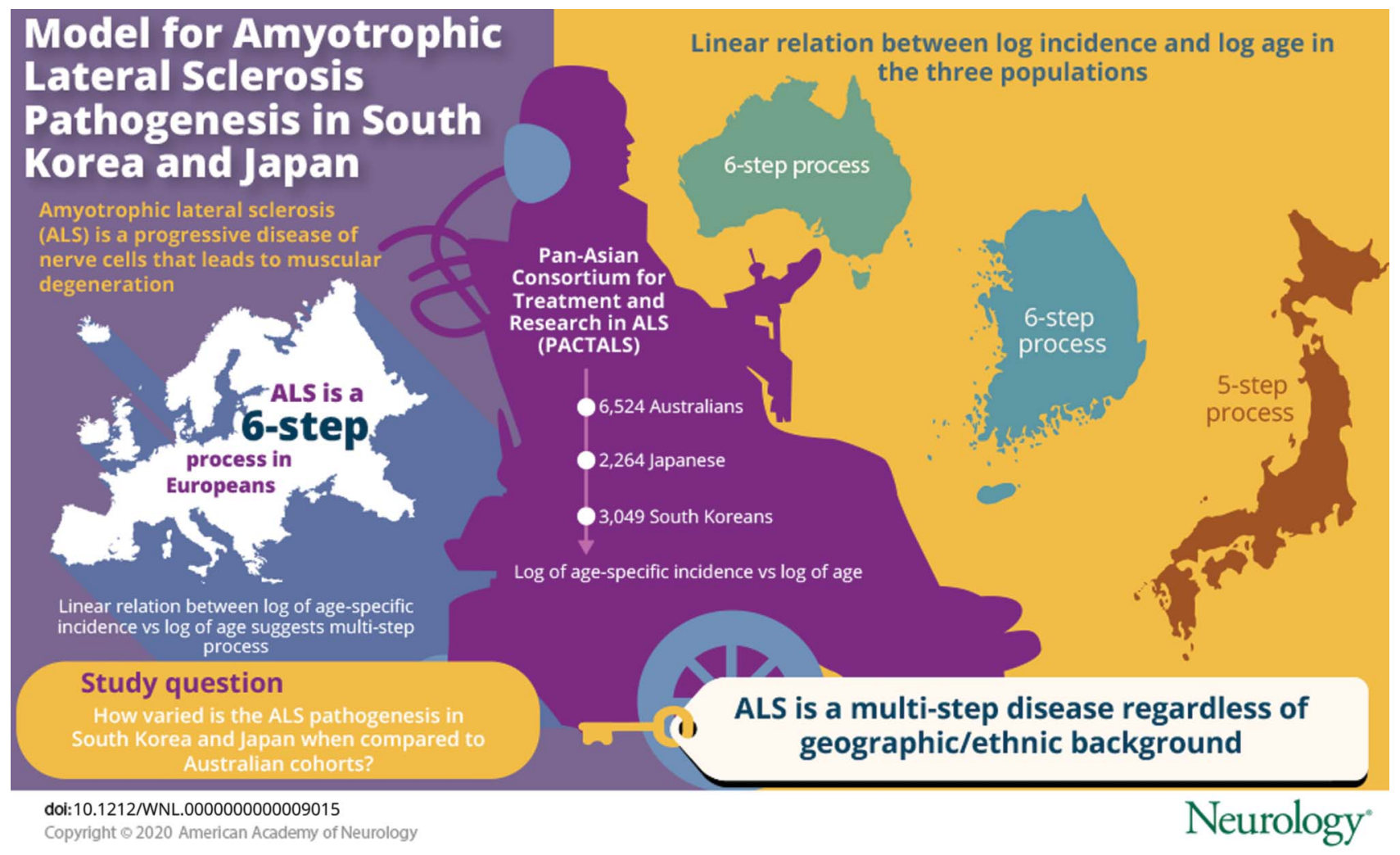

The pathophysiologic mechanisms underlying the development of amyotrophic lateral sclerosis (ALS) remain to be fully clarified, although there are indications that the degenerative process is the consequence of a complex interaction between genetic and environmental factors, leading to dysfunction of critical molecular pathways. ${ }^{1,2}$ More than 20 different genes have been linked to ALS causality, ${ }^{3}$ with approximately $20 \%$ of ALS heritability attributed to common genetic variations. ${ }^{4}$ Environmental factors have also been implicated in ALS pathogenesis. ${ }^{5}$ Although exposure to individual environmental factors is weakly causal, cumulative exposure is likely to exceed the disease-onset threshold leading to development of ALS. ${ }^{6}$ Separately, epigenetic modifications are increasingly recognized as an important mechanism in ALS pathogenesis, ${ }^{7}$ potentially providing a link between genetic predisposition and cumulative environmental exposure.

A multistep process, requiring exposure to 6 factors, was identified as a likely pathogenic model for sporadic ALS in a large European cohort. ${ }^{8}$ A mathematical modeling approach, adapted from cancer studies, ${ }^{9,10}$ demonstrated a linear relationship between the natural log incidence and log age, indicating that sporadic ALS was a multistep process. $^{8}$ Subsequently, a multistep process was reported in an Australian ALS cohort (of predominant European background), indicating that 6 steps were required for ALS development. ${ }^{11} \mathrm{~A}$ reduced number of steps were reported for patients with familial ALS, being 2 steps for SOD1 gene mutations, 3 for c9orf72, and 4 for TARDBP mutations, ${ }^{12}$ indicating that while genetic factors strongly predispose to development of ALS, nongenetic factors also appear to be important.

Geographic differences in ALS incidence have been documented, with incidence being highest in the European (Caucasian) and lowest in southeast Asian patients. ${ }^{13}$ The origin of these geographic differences remains a matter of debate, being ascribed to variations in genetic and environmental factors as well as life expectancy. ${ }^{13}$ Furthermore, it could be argued that a greater number of steps are required to develop ALS in the Asian population, thereby leading to lower incidence rates. Establishing a multistep model in the South Korean and Japanese ALS population, particularly the number of required steps, could be of pathophysiologic importance. Consequently, the present study employed a mathematical modeling approach in a group of Japanese and South Korean patients with ALS to determine whether ALS was a multistep process and whether the number of steps required for disease development was different when compared with the Australian patients with ALS, who are largely of European ancestry. 


\section{Methods}

This study stemmed from an international collaboration made possible by the recent establishment of the Pan-Asian Consortium for Treatment and Research in ALS (PACTALS). ${ }^{14}$ Incident data by age and sex were provided for the Japanese (collected between April 2009 and March 2010) ${ }^{15}$ and South Korean ALS cohorts (January 2011 and December 2015). ${ }^{16}$ The Japanese patients with ALS were diagnosed according to the revised El Escorial criteria (definite, probable, or possible) ${ }^{17}$ and the South Korean patients with ALS were diagnosed with sporadic ALS according to the Korean Classification of Disease 6, which is based on the ICD-10. ${ }^{16}$ Crude mortality rates were provided by the Australian Institute of Health and Welfare (from 2007 to 2016, ICD-1012.20) and used as a measure of incident rates. The data used for the Australian ALS cohort have been previously reported in part, ${ }^{11}$ although the age at onset windows were shortened (30-80 years of age, compared to 30-85 years), divided into 10-year epochs (as opposed to 5 -year epochs), and reanalyzed with respect to age at onset using a recently developed predictive model. ${ }^{18}$

The Armitage and Doll methodology, ${ }^{9}$ recently adapted for ALS, ${ }^{8,12}$ was utilized to determine whether ALS was a multistep process in the 3 different populations. In this model, the plot of natural log of ALS incidence vs the natural log age will be linear in a multistep process. ${ }^{8}$ The gradient of the linear regression will be $\mathrm{n}-1$, where $\mathrm{n}$ reflects the number of steps required to develop ALS. The older age groups ( $>85$ years) have to be excluded from this analysis as the linear relationship does not hold true at these ages.

\section{Statistical analysis}

The incident rates were provided for age groups $20-80+$ years for the Japanese and South Korean patients with ALS, while crude mortality rates (deaths per 100,000) were provided for age groups $15-85$ years in the Australian cohort. The data were divided into 10-year age groups with extreme age groups ( $<30$ and $>80$ years) excluded in order to reduce the chance of measurement errors. ${ }^{8}$ In order to estimate the age at disease onset in the Australian ALS cohort, a recently developed predictive model for ALS was used to estimate the median survival and consequently age at disease onset. ${ }^{18}$ The crude mortality rates were used as a reflection of incidence rates for ALS. The natural log of ALS incidence was subsequently plotted against the log of age using linear regression. Regression analysis was unweighted such that the slope was not biased towards the older age groups. The slope was calculated for the total cohort, as well as male and female patients with ALS, from the 3 different cohorts. All data are expressed as mean \pm SD. The $95 \%$ confidence intervals (CIs) were calculated for the slope estimates.

\section{Standard protocol approvals, registrations, and patient consents}

Deidentified data were provided by the Australian Institute of Health and Welfare, which conformed with requirements of the Privacy Act 1998 and Australian Institute of Health and Welfare
Act 1987. Individual consent is not required for use of these data, which have been previously published in part. ${ }^{11}$ Additional deidentified data were incorporated from the Australian Motor Neurone Disease Registry, for which patients provided written informed consent. ${ }^{19}$ Deidentified data were obtained on Japanese patients with ALS from all prefectural offices. ${ }^{15}$ The study was approved by the institutional review board (IRB) of the National Institute of Public Health, Japan (NIPHTRN\# 12009). Korean data were derived from the National Health Insurance Database, which includes information on the insured population's sociodemographic characteristics, income-based insurance contributions, medical treatment records, long-term care insurance information for elderly patients, and rates of cancer and rare incurable diseases. Deidentified data on mortality and incidence on patients with ALS were collected from Statistics Korea, and ethics approval was obtained from the local IRB (HYUH IRB 2013-08-022, HYU-16-123-1). Some data on the South Korean patient cohort were previously published in part. ${ }^{16}$

\section{Data availability}

Anonymized data not published within this article will be made available by request from any qualified investigator.

\section{Results}

In total, data were provided on 11,834 cases of ALS from 3 PACTALS sites (Australia, Japan, and South Korea). ${ }^{14}$ Specifically, data were collected for 2,263 Japanese and 3,049 South Korean patients with ALS, with results compared to 6,524 Australian (nonindigenous) patients. The aged standardized incident rates were highest in the Australian patients $(2.9,2.5-3.4)$, followed by the Japanese patients with ALS $(2.3,2.2-2.4)$, and were lowest in the South Korean ALS cohort $(0.88,0.81-0.95)$. Male:female ratio was highest in the South Korean patients (1.6:1), followed by the Japanese (1.5: 1) and Australian (1.3:1) patients with ALS. The crude incident rates peaked at ages $70-79$ years for all 3 populations.

The relationship between the log incidence and log age was linear in all 3 cohorts. The $r^{2}$ values were 0.99 in the 3 populations (figure 1). This finding is in keeping with previous studies conducted in the European ALS populations, ${ }^{8,12}$ and is consistent with a multistep process. Of further relevance, theslope $(n-1)$ of the linear curve was 5.4 (95\% CI, 4.8-5.5) in the Japanese patients with ALS, 5.4 (95\% CI, 5.2-5.7) in the Australian, and 4.4 (95\% CI, 4.2-4.8) in the South Korean cohorts (figure 1).

There was a subtle sex difference between the slope estimates across the 3 ALS populations. In the Japanese cohort, the slope for male patients with ALS (5.6; 95\% CI, 5.2-6.0) was higher when compared to female patients ( 4.9 ; $95 \% \mathrm{CI}, 4.3-5.0$ ), while the converse was evident in the Australian patients with ALS (male 5.0; 95\% CI, 4.7-5.4; female 5.5; 95\% CI, 5.0-6.0). In the South Korean patients with ALS, the slope for male and female 


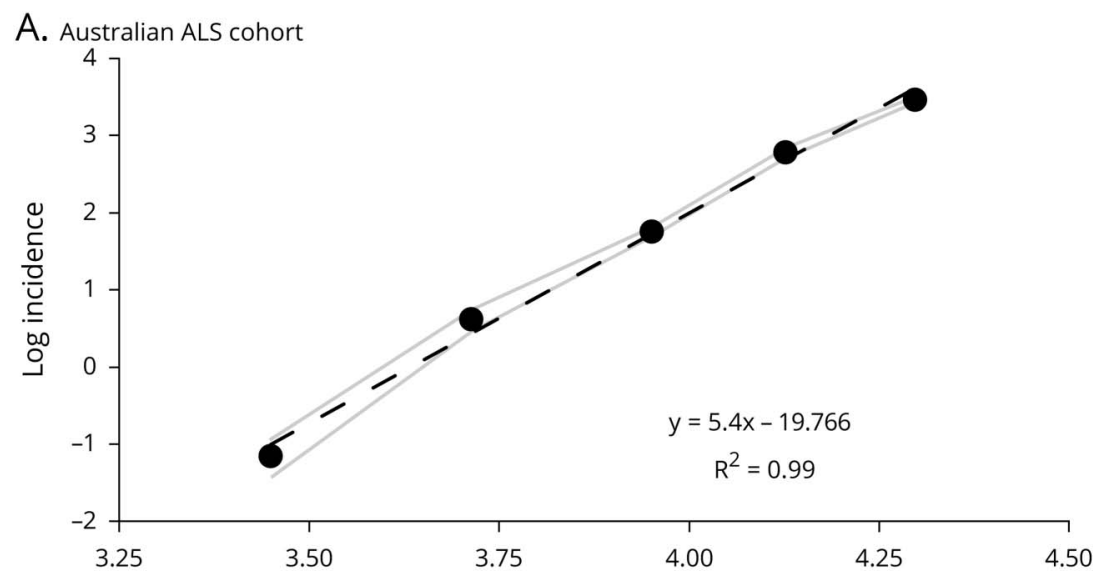

B. Japanese ALS cohort
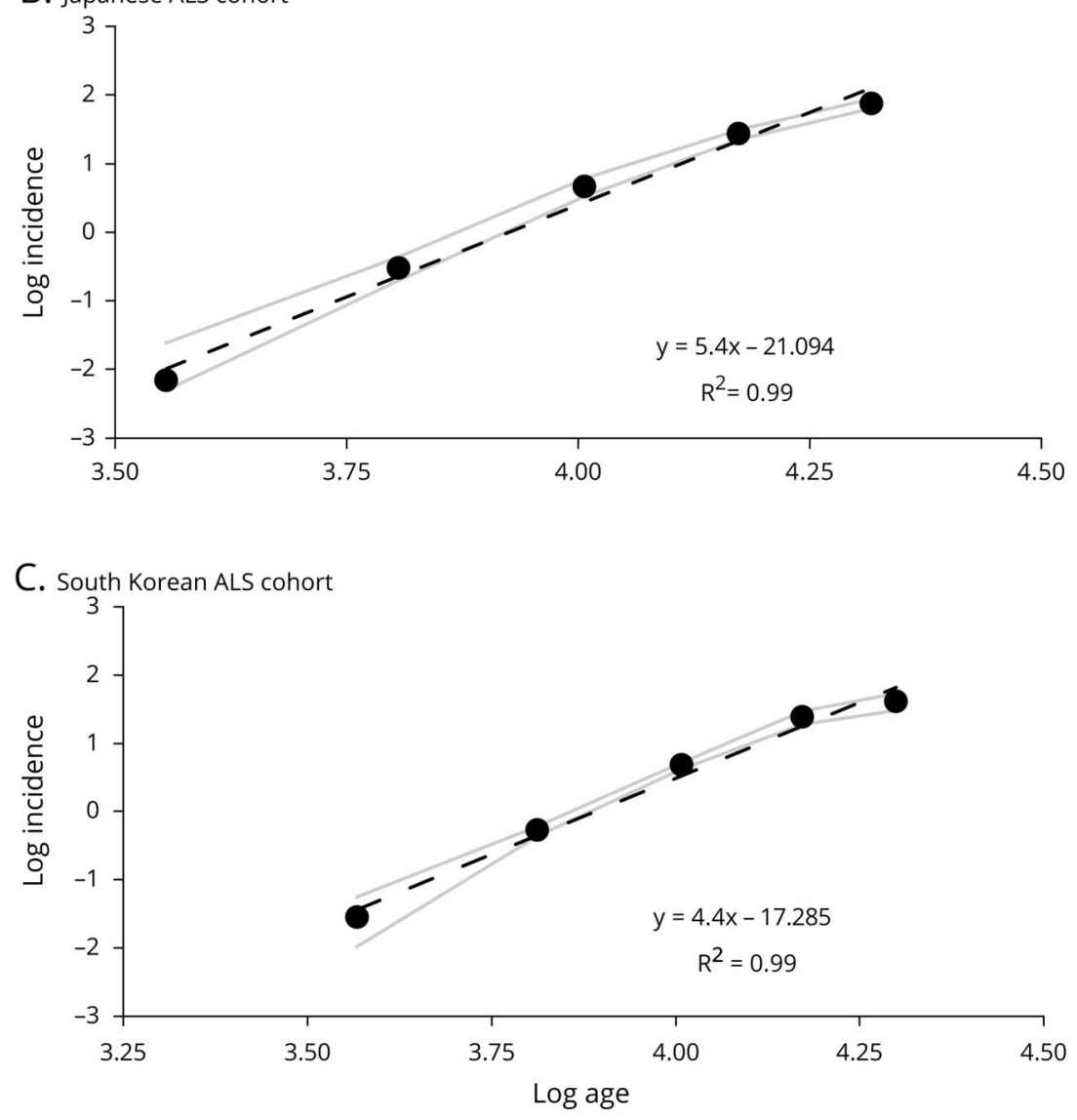

Slope estimates calculated by expressing the log incidence vs log age were (A) 5.4 in Australian patients with amyotrophic lateral sclerosis (ALS), (B) 5.4 in Japanese patients with ALS, and (C) 4.4 in South Korean patients with ALS. The $95 \%$ confidence intervals are highlighted by the gray lines.

patients was similar (male 4.5, 95\% CI, 4.2-4.8; female 4.6, 95\% CI, 4.1-5.2). Importantly, a linear relationship between log incidence and log age was evident in both sexes across the 3 populations, with $r^{2}$ values being virtually identical (Australian patients with ALS, 0.99 for male patients and 0.98 for female patients; Japanese patients with ALS, 0.98 for male and female patients; South Korean patients with ALS, 0.98 for male and 0.99 for female patients; figure 2). Taken together, these findings underscore the notion that ALS is a multistep process irrespective of sex.

\section{Discussion}

The present study has established a linear relationship between the log incidence and log age at onset across 3 ethnically diverse populations, suggesting that ALS is a multistep process irrespective of ethnic background and in keeping with previous studies. ${ }^{8,11,12}$ The slope estimates were 5 for the Australian and Japanese ALS cohorts, thereby suggesting a 6-step process, while in the South Korean patients with ALS the slope estimate was 4, indicating a 5-step process. At a pathophysiologic level, 


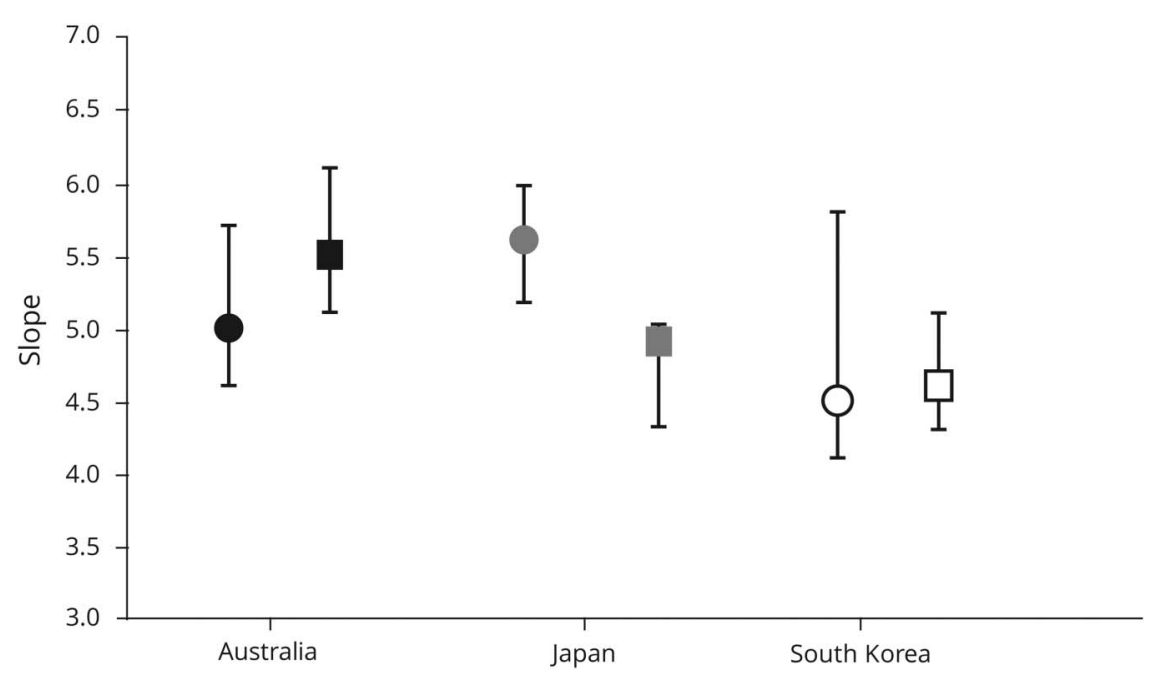

Whereas 6 steps were modeled for male Australian patients and 7 steps were evident in female patients, the converse was observed in the Japanese patients with ALS (7 steps for male patients and 6 steps for female patients). In the South Korean patients with ALS, the slope estimates for male and female patients with ALS were similar. Irrespective of the subtle sex differences in slope estimates, the strong linear relationship was maintained, indicating that ALS was a multistep process across the different ethnic populations. Circles, men; squares, women. the present study implies a similarity of mechanisms across the 3 populations with multiple steps required to develop ALS. The implications of the modeling study for the understanding of ALS pathogenesis is discussed further.

\section{Pathophysiologic mechanisms underlying ALS}

The pathophysiologic mechanisms underlying the development of ALS remain to be elucidated, although a complex interaction among genetic, epigenetic, and environmental factors seems likely. ${ }^{1,2,7}$ In keeping with the established complexity of ALS pathogenesis, a multistep process requiring 6 steps was reported in Caucasian patients ${ }^{8}$ and reaffirmed in a recent Australian study. ${ }^{11}$ The present study provides additional evidence for a multistep process in ALS by establishing a consistency of slope estimates across diverse ethnic populations, reassuring the veracity of the statistical methodology. The current study design was not identical to previous studies in that 10-year epochs were used and the population age span was contracted (30-79 years). Irrespective of these differences, a strong linear relationship between log incidence and log age along with comparable slope estimate values was established across the 3 populations, providing additional evidence for a multistep process in ALS.

Establishing ALS as a multistep process in diverse ethnic populations has profound implications for the understanding of its pathogenesis. A multistep process would provide an elegant explanation for the notion that the seeds for developing ALS occur during the neonatal period. ${ }^{6,20}$ The mechanism by which neonatal events trigger the development of ALS later in life remains hypothetical, although there is precedence with other neurobiological diseases. ${ }^{21}$ During embryogenesis, synchronized and complex neuronal activity evolves with brain development, which is essential for neurogenesis, development of neuronal circuitry, cell migration and differentiation, programmed cell death, as well establishment of axonal connections. $^{21}$ Neonatal insults, such as hypoxia or inflammation, result in permanent dysfunction of cortical architecture and physiology. ${ }^{22-24}$ Deleterious effects are particularly exerted on the GABAergic circuits, resulting in disordered cortical excitatory/inhibitory balance, which is crucial for normal brain functioning. ${ }^{25}$ While epidemiologic studies have not as yet linked neonatal insults with ALS, well-established conditions such as autism spectrum disorder, schizophrenia, and depression are associated with perinatal insults. ${ }^{21}$ Investigating the role of neonatal and other factors in ALS development, as part of a multistep model, may prove challenging. Longitudinal assessment of cortical excitability (using neurophysiologic techniques such as transcranial magnetic stimulation), along with in-depth clinical phenotyping, genomic, proteomic, and environmental exposure profiling, could be undertaken on children born to parents with ALS, as well as the patients with ALS, with appropriate ethical considerations. These findings should be ultimately linked to pathologic findings on postmortem studies. Such an approach may uncover the precise sequence of steps involved in ALS onset, resulting in a clearer understanding of disease pathogenesis.

Phenotypic expression with seemingly critical genetic ALS mutations in later stages of life, as well as variability of phenotypic expression, may also be explained by a multistep process. ${ }^{26}$ Exposure to critical events during the neonatal period or inheritance of specific ALS genetic mutations could represent an initial step for development of ALS. Importantly, neonatal or genetic factors could contribute to more than one step, explaining the variability in the ALS phenotype. Underscoring this notion is the effect of genetic mutations on the number of steps required for ALS development. ${ }^{12}$ Notably, mutations in the superoxide dismuate-1 (SOD1) gene require 2 additional steps to express the phenotype, while 3 steps are needed for C9orf72 expansions and 4 for TARDBP mutations, contrasting with sporadic ALS. ${ }^{12}$ Unraveling the dynamics governing the 
multistep process could be critical for enhancing the understanding of ALS pathogenesis as well as developing novel therapeutic targets.

Interaction between genetic and neonatal factors with environmental influences appears to be important in ALS pathophysiology. ${ }^{6}$ A prolonged preclinical phase has been proposed in $\mathrm{ALS}^{6}$ during which there seem to be critical interactions among genetic, neonatal, and environmental factors. ${ }^{27}$ Along these lines, it has been shown that prolonged exposure to environmental toxins, along with excessive physical activity and dietary changes, have been associated with ALS development. ${ }^{26,28}$ In isolation, these factors may be insufficient to trigger ALS, although sustained exposure and interactions with genetic and molecular processes in a multistep process may trigger ALS development.

Geographic differences in ALS incidence have been well established, with ALS being more prevalent in Caucasian than Asian populations, ${ }^{13}$ an observation upheld in the present study. The etiology of these geographic differences remains to be resolved, although may relate to genetic, neonatal, and environmental factors. While Japanese and South Korean populations have common ancestors, dating back to $\sim 3,000-3,600$ years ago, subtle genetic variations have been reported and ascribed to geographical isolation and segregation. ${ }^{29}$ The Northern European and Mediterranean European populations, which comprise the majority of the Australian ALS cohort, exhibit distinct genotype clusters when compared to Japanese and Korean populations. ${ }^{30}$ Consequently, it could also be argued that subtle genetic differences could affect the pathogenic processes underlying ALS development across different ethnic groups, with Japanese and South Korean patients being more resistant to developing ALS. While subtle differences in slope estimates were evident, with 5 steps modeled for the South Korean patients, the strong linear relationship between log age and $\log$ incidence across the 3 populations suggests that ALS is a multistep process irrespective of ethnic origins. The differences in slope estimates could relate to subtle differences in the definition of ALS across the 3 populations. As such, the geographic differences may relate to the level of epigenetic and environmental factor exposure, with the South Korean patients being exposed to less frequent or different insults. The present study did not find any meaningful differences in ALS on the basis of race, and in fact a difference between cohorts of similar ethnicity was noted (Japanese vs South Korean).

Interestingly, genetic studies conducted on Korean and Japanese patients with ALS have disclosed a greater frequency of SOD1 and FUS mutations when compared to European ALS cohorts, while C9orf 72 hexanucleotide expansions are either absent or extremely infrequent. ${ }^{31-34}$ In addition, other pathogenic ALS genes (including TARDBP, VCP, OPTN, ANG, and TBK1) have been infrequently detected in the Korean and Japanese ALS population. ${ }^{31-34}$ Consequently, genetic diversity may affect the causes of familial ALS between the Caucasian and the Korean/Japanese populations. Future studies should assess whether a multistep model is evident in Korean and Japanese patients with familial ALS, and determine whether the number of steps are congruent to that reported in Caucasian familial ALS cohorts. ${ }^{12}$

The present study established ALS as a multistep process in Australian (European ancestry), Korean, and Japanese patients with ALS. Five steps were required in the South Korean patients with ALS while 6 steps were needed in the Australian and Japanese patients for disease onset. Our findings are congruent with previous European studies, ${ }^{8,28}$ underscoring the veracity of a multistep process in ALS. Identification of the pathogenic steps will enhance the understating of ALS and ultimately lead to development of effective therapies.

\section{Author contributions}

S. Vucic: drafting/revising the manuscript, data acquisition, study concept or design, analysis or interpretation of data, accepts responsibility for conduct of research and final approval, acquisition of data, statistical analysis, study supervision. M. Higashihara: drafting/revising the manuscript, data acquisition, analysis or interpretation of data, accepts responsibility for conduct of research and final approval, acquisition of data, statistical analysis. G. Sobue: study concept or design, accepts responsibility for conduct of research and final approval, study supervision. N. Atsuta: data acquisition, analysis or interpretation of data, accepts responsibility for conduct of research and final approval, study supervision. Y. Doi: data acquisition, accepts responsibility for conduct of research and final approval. S.H. Kuwabara: analysis or interpretation of data, accepts responsibility for conduct of research and final approval, acquisition of data. S.H. Kim: drafting/revising the manuscript, data acquisition, accepts responsibility for conduct of research and final approval, acquisition of data, obtaining funding. I. Kim: data acquisition, analysis or interpretation of data, accepts responsibility for conduct of research and final approval, acquisition of data, statistical analysis. K.-W. Oh: drafting/revising the manuscript, data acquisition, analysis or interpretation of data, accepts responsibility for conduct of research and final approval, acquisition of data. J. Park: drafting/revising the manuscript, data acquisition, accepts responsibility for conduct of research and final approval, acquisition of data, statistical analysis. E.M. Kim: analysis or interpretation of data, accepts responsibility for conduct of research and final approval, acquisition of data, statistical analysis. P. Talman: drafting/ revising the manuscript, accepts responsibility for conduct of research and final approval, acquisition of data. P. Menon: data acquisition, accepts responsibility for conduct of research and final approval. M.C. Kiernan: drafting/revising the manuscript, data acquisition, study concept or design, analysis or interpretation of data, accepts responsibility for conduct of research and final approval, acquisition of data, study supervision, obtaining funding.

\section{Study funding}

This study was supported by research grants from the Motor Neuron Disease Research Institute of Australia, National 
Health and Medical Research Council of Australia (project grant numbers 510233, 1024915, 1055778), and the Brain Research Program of the National Research Foundation (NRF) funded by the Korean Ministry of Science \& ICT (NRF-2018M3C7A1056512). This work was also supported by funding to Forefront, a collaborative research group dedicated to the study of frontotemporal dementia and motor neuron disease, from the National Health and Medical Research Council of Australia (program grant \#1037746).

\section{Disclosure}

S. Vucic discloses being web editor for Journal of Neurology, Neurosurgery and Psychiatry. M. Higashihara, G. Sobue, N. Atsuta, Y. Doi, S. Kuwabara, S. Kim, I. Kim, K. Oh, J. Park, E. Kim, P. Talman, and P. Menon report no disclosures relevant to the manuscript. M. Kiernan is editor of Journal of Neurology, Neurosurgery and Psychiatry. Go to Neurology.org/N for full disclosures.

\section{Publication history}

Received by Neurology August 6, 2019. Accepted in final form November 8, 2019.

\section{References}

1. Geevasinga N, Menon P, Ozdinler PH, Kiernan MC, Vucic S. Pathophysiological and diagnostic implications of cortical dysfunction in ALS. Nat Rev Neurol 2016;12:651-661.

2. Kiernan MC, Vucic S, Cheah BC, et al. Amyotrophic lateral sclerosis. Lancet 2011; 377:942-955.

3. Brown RH, Al-Chalabi A. Amyotrophic lateral sclerosis. N Engl J Med 2017;377: $162-172$.

4. McLaughlin RL, Vajda A, Hardiman O. Heritability of amyotrophic lateral sclerosis: insights from disparate numbers. JAMA Neurol 2015;72:857-858.

5. Lian L, Liu M, Cui L, et al. Environmental risk factors and amyotrophic lateral sclerosis (ALS): a case-control study of ALS in China. J Clin Neurosci 2019;66:12-18.

6. Eisen A, Kiernan M, Mitsumoto H, Swash M. Amyotrophic lateral sclerosis: a long preclinical period? J Neurol Neurosurg Psychiatry 2014;85:1232-1238.

7. Bennett SA, Tanaz R, Cobos SN, Torrente MP. Epigenetics in amyotrophic lateral sclerosis: a role for histone post-translational modifications in neurodegenerative disease. Transl Res 2019;204:19-30.

8. Al-Chalabi A, Calvo A, Chio A, et al. Analysis of amyotrophic lateral sclerosis as a multistep process: a population-based modelling study. Lancet Neurol 2014;13:1108-1113.

9. Armitage P, Doll R. The age distribution of cancer and a multi-stage theory of carcinogenesis. Br J Cancer 1954;8:1-12.

10. Fisher JC, Hollomon JH. A hypothesis for the origin of cancer foci. Cancer 1951;4: 916-918.

11. Vucic S, Westeneng HJ, Al-Chalabi A, van den Berg LH, Talman P, Kiernan MC. Amyotrophic lateral sclerosis as a multi-step process: an Australia population study. Amyotroph Lateral Scler Frontotemporal Degener 2019;8:1-6.
12. Chio A, Mazzini L, D'Alfonso S, et al. The multistep hypothesis of ALS revisited: the role of genetic mutations. Neurology 2018;91:e635-e642.

13. Logroscino G, Piccininni M. Amyotrophic lateral sclerosis descriptive epidemiology: the origin of geographic difference. Neuroepidemiology 2019;52:93-103.

14. Shahrizaila N, Sobue G, Kuwabara S, et al. Amyotrophic lateral sclerosis and motor neuron syndromes in Asia. J Neurol Neurosurg Psychiatry 2016;87:821-830.

15. Doi Y, Atsuta N, Sobue G, Morita M, Nakano I. Prevalence and incidence of amyotrophic lateral sclerosis in Japan. J Epidemiol 2014;24:494-499.

16. Jun KY, Park J, Oh KW, et al. Epidemiology of ALS in Korea using nationwide big data. J Neurol Neurosurg Psychiatry 2019;90:395-403.

17. Brooks B, Miller R, Swash M, Munsat T. El Escorial revisited: revised criteria for the diagnosis of amyotrophic lateral sclerosis. Amyotroph Lateral Scler Other Mot Neuron Disord 2000;1:293-299.

18. Westeneng HJ, Debray TPA, Visser AE, et al. Prognosis for patients with amyotrophic lateral sclerosis: development and validation of a personalised prediction model. Lancet Neurol 2018;17:423-433.

19. Talman P, Duong T, Vucic $S$, et al. Identification and outcomes of clinical phenotypes in amyotrophic lateral sclerosis/motor neuron disease: Australian National Motor Neuron Disease observational cohort. BMJ Open 2016;6:e012054.

20. Kiernan MC, Ziemann U, Eisen A. Amyotrophic lateral sclerosis: origins traced to impaired balance between neural excitation and inhibition in the neonatal period. Muscle Nerve 2019;60:232-235.

21. Rossignol E. Genetics and function of neocortical GABAergic interneurons in neurodevelopmental disorders. Neural Plast 2011;2011:649325.

22. Louzoun-Kaplan V, Zuckerman M, Perez-Polo JR, Golan HM. Prenatal hypoxia down regulates the GABA pathway in newborn mice cerebral cortex; partial protection by MgSO4. Int J Dev Neurosci 2008;26:77-85.

23. Allain AE, Le Corronc H, Delpy A, et al. Maturation of the GABAergic transmission in normal and pathologic motoneurons. Neural Plast 2011;2011:905624.

24. Brostrom L, Vollmer B, Bolk J, Eklof E, Aden U. Minor neurological dysfunction and associations with motor function, general cognitive abilities, and behaviour in children born extremely preterm. Dev Med Child Neurol 2018;60: $826-832$.

25. Wu C, Sun D. GABA receptors in brain development, function, and injury. Metab Brain Dis 2015;30:367-379.

26. Al-Chalabi A, Hardiman O. The epidemiology of ALS: a conspiracy of genes, environment and time. Nat Rev Neurol 2013;9:617-628.

27. Lynch KE, Kemp DJ. Nature-via-nurture and unravelling causality in evolutionary genetics. Trends Ecol Evol 2014;29:2-4.

28. Chio A, Benzi G, Dossena M, Mutani R, Mora G. Severely increased risk of amyotrophic lateral sclerosis among Italian professional football players. Brain 2005;128: $472-476$.

29. Wang Y, Lu D, Chung YJ, Xu S. Genetic structure, divergence and admixture of Han Chinese, Japanese and Korean populations. Hereditas 2018;155:19.

30. Pakstis AJ, Gurkan C, Dogan M, et al. Genetic relationships of European, Mediterranean, and SW Asian populations using a panel of 55 AISNPs. Eur J Hum Genet 2019;27:1885-1893.

31. Jang JH, Kwon MJ, Choi WJ, et al. Analysis of the C9orf72 hexanucleotide repeat expansion in Korean patients with familial and sporadic amyotrophic lateral sclerosis. Neurobiol Aging 2013;34:1311.e7-1311.e9.

32. Kim HJ, Oh KW, Kwon MJ, et al. Identification of mutations in Korean patients with amyotrophic lateral sclerosis using multigene panel testing. Neurobiol Aging 2016;37: 209.e209-209.e216.

33. Kwon MJ, Baek W, Ki CS, et al. Screening of the SOD1, FUS, TARDBP, ANG, and OPTN mutations in Korean patients with familial and sporadic ALS. Neurobiol Aging 2012;33:1017.e17-1017.e23.

34. Nakamura R, Sone J, Atsuta N, et al. Next-generation sequencing of 28 ALS-related genes in a Japanese ALS cohort. Neurobiol Aging 2016;39:219.e1-219.e8. 


\section{Neurology}

ALS is a multistep process in South Korean, Japanese, and Australian patients Steve Vucic, Mana Higashihara, Gen Sobue, et al.

Neurology 2020;94;e1657-e1663 Published Online before print February 18, 2020

DOI 10.1212/WNL.0000000000009015

This information is current as of February 18, 2020

\section{Updated Information \&} Services

References

Citations

Subspecialty Collections

Errata

Permissions \& Licensing

Reprints including high resolution figures, can be found at: http://n.neurology.org/content/94/15/e1657.full

This article cites 34 articles, 5 of which you can access for free at: http://n.neurology.org/content/94/15/e1657.full\#ref-list-1

This article has been cited by 1 HighWire-hosted articles: http://n.neurology.org/content/94/15/e1657.full\#\#otherarticles

This article, along with others on similar topics, appears in the following collection(s):

Amyotrophic lateral sclerosis

http://n.neurology.org/cgi/collection/amyotrophic_lateral_sclerosis_

An erratum has been published regarding this article. Please see next page or:

/content/97/3/151.3.full.pdf

Information about reproducing this article in parts (figures,tables) or in its entirety can be found online at:

http://www.neurology.org/about/about_the_journal\#permissions

Information about ordering reprints can be found online:

http://n.neurology.org/subscribers/advertise

Neurology ${ }^{\circledR}$ is the official journal of the American Academy of Neurology. Published continuously since 1951, it is now a weekly with 48 issues per year. Copyright Copyright @ 2020 The Author(s). Published by Wolters Kluwer Health, Inc. on behalf of the American Academy of Neurology.. All rights reserved. Print ISSN: 0028-3878. Online ISSN: 1526-632X.

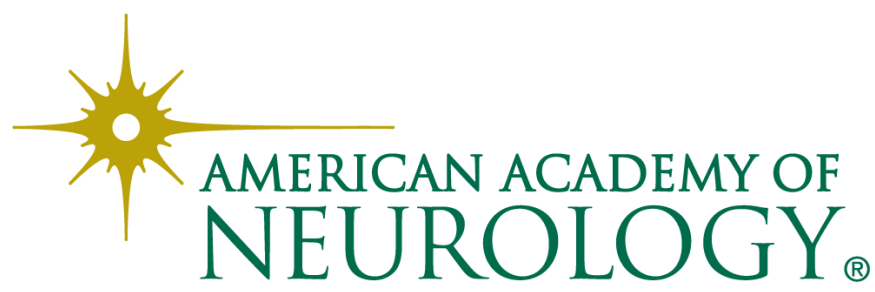




\title{
Disputes \& Debates: Editors' Choice
}

Steven Galetta, MD, FAAN, Editor

Aravind Ganesh, MD, DPhil, FRCPC, Deputy Editor

Ariane Lewis, MD, Deputy Editor

James E. Siegler III, MD, Deputy Editor

\section{Editors' Note: Cause of Death in Spontaneous Intracerebral Hemorrhage Survivors: Multistate Longitudinal Study}

Using administrative claims data from 3 US states, Dr. Kuohn et al. report the long-term mortality rate of survivors with spontaneous intracerebral hemorrhage (ICH). Using an original population of 104,000 patients who were screened for eligibility, 72,432 survivors of the index hospitalization were followed for a median of 4 years. The 1-year risk of death or discharge to hospice was $9.5 \%$ (95\% CI 9.2\%-9.7\%), with the most common proximate causes of death being infection (34\%) or subsequent intracranial hemorrhage (13\%). The median time from ICH to death was 10 months (IQR 2-31 months). Dr. Llamas-Nieves and colleagues highlight the importance of confounders such as diabetes, which was independently associated with death as shown in the multivariable regression model (HR $1.22,95 \%$ CI 1.17-1.27), as this may be an important mediator of death because of infectious causes. The investigators acknowledge that diabetes contributes to death in the overall population; however, it was not independently associated with death due to infection (OR 1.16, 95\% CI 0.86-1.55). The authors posit that diabetes (as well as age, postICH disability, and other comorbidities) are important contributors to the development of later infection, but it remains unclear why diabetes is not an independent modifier of death risk among patients who develop infection.

James E. Siegler, MD, and Steven Galetta, MD

Neurology ${ }^{\circledR}$ 2021;97:148. doi:10.1212/WNL.0000000000012281

\section{Reader Response: Cause of Death in Spontaneous Intracerebral Hemorrhage Survivors: Multistate Longitudinal Study}

\author{
Andrés E. Llamas-Nieves (Cartagena, Colombia), Ivan D. Lozada-Martinez (Cartagena, Colombia), \\ Daniela M. Torres-Llinás (Cartagena, Colombia), and Luis R. Moscote-Salazar (Cartagena, Colombia) \\ Neurology ${ }^{\circledR}$ 2021;97:148-149. doi:10.1212/WNL.0000000000012282
}

We read with great interest the recent article by Kuohn et al. ${ }^{1}$ The authors conducted a comprehensive review on the factors associated with mortality in patients who survived spontaneous intracerebral hemorrhage, where they showed that the infection was the main cause of death in such a group with a value of $34 \%$. However, they do not emphasize other comorbidities that could have influenced the morbidity and mortality of patients in the infection group, such as diabetes. Diabetes is a disease that increases susceptibility to infections such as those involving the skin, urinary tract, or lungs. ${ }^{2}$ Lau et al. performed a systematic review and meta-analysis, where they found that isolated diabetes is strongly associated with poor prognosis after stroke, including increased morbidity, mortality, and disability. ${ }^{3}$ For this reason, it is very important to know the factors that underlie and really impact on the subject of study, to obtain certainty in the 
results of the research, and to avoid underestimations as what likely happened in the study of Kuohn et al. We suggest separate future study groups to avoid this type of bias during data analysis.

1. Kuohn LR, Leasure AC, Acosta JN, et al. Cause of death in spontaneous intracerebral hemorrhage survivors Multistate longitudinal study. Neurology. 2020;95(20):e2736-e2745.

2. Pannu AK, Saroch A, Singla V, et al. Clinical spectrum, etiology and outcome of infectious disease emergencies in adult diabetic patients in northern India. Diabetes Metab Syndr. 2020;14(5):921-925.

3. Lau L-H, Lew J, Borschmann K, Thijs V, Ekinci EI. Prevalence of diabetes and its effects on stroke outcomes: a meta-analysis and literature review. J Diabetes Investig. 2019;10(3):780-792.

Copyright (c) 2021 American Academy of Neurology

\section{Author Response: Cause of Death in Spontaneous Intracerebral Hemorrhage Survivors: Multistate Longitudinal Study}

Lindsey Kuohn (New York) and Kevin Sheth (New Haven, CT)

Neurology ${ }^{\circledR}$ 2021;97:149. doi:10.1212/WNL.0000000000012283

We thank Dr. Llamas-Nieves et al. for their interest in our article ${ }^{1}$ and recognize that coexisting diabetes, among other comorbidities, may influence infection-related mortality in ICH survivors. We hypothesized that the high proportion of deaths caused by infections may be due to the burden of disability in this population. Intracerebral hemorrhage ( $\mathrm{ICH}$ ) survivors often require chronic hospitalization and are prone to infections such as Clostridium difficile, urinary tract infections, and aspiration pneumonia. Our finding that older age was an independent risk factor for death caused by infection supports this hypothesis. However, we agree that increased susceptibility to infection in patients with diabetes should be considered as a potential driver of infection-related deaths in patients with $\mathrm{ICH}^{2}$ Diabetes was included as a covariate in the adjusted multinomial logistic regression model of causes of death during follow-up in our study (table 3). Diabetes was not associated with increased odds of death caused by infection (odds ratio 1.16, 95\% confidence interval 0.86-1.55), although diabetes did correlate with increased risk for death overall (hazard ratio $1.22,95 \%$ confidence interval 1.17-1.27). The cause of elevated mortality after ICH in patients with diabetes is not clear, and our results are not conclusive regarding the potential association with infection. As Dr. Llama-Nieves et al. point out, future studies of the specific causes of infection-related morbidity and mortality are warranted and necessary to improve long-term outcomes after ICH.

1. Kuohn LR, Leasure AC, Acosta JN, et al. Cause of death in spontaneous intracerebral hemorrhage survivors: multistate longitudinal study. Neurology. 2020;95(20):e2736-e2745.

2. Moutschen MP, Scheen AJ, Lefebvre PJ. Impaired immune responses in diabetes mellitus: analysis of the factors and mechanisms involved. Relevance to the increased susceptibility of diabetic patients to specific infections. Diabete Metab. 1992;18(3): $187-201$.

Copyright (c) 2021 American Academy of Neurology

Author disclosures are available upon request (journal@neurology.org). 


\section{Editors' Note: Sex, Race, and Risk of Dementia Diagnosis After Traumatic Brain Injury Among Older Veterans}

Traumatic brain injury (TBI) has a well-known association with cognitive impairment and dementia. Whether there is a differential risk of dementia after TBI based on sex, race, or ethnicity was the subject of the recently published retrospective cohort study by Dr. Kornblith et al. Using a $2 \%$ random sample of claims data from Veterans Health Administration systems databases $(n=999,640)$, investigators evaluated the cumulative incidence of all-cause dementia by age, sex, race, and ethnicity. They found a significant interaction between TBI and race for dementia, in which White veterans were at the highest risk for dementia diagnoses. Dr. Roberts affirms these findings are consistent with the literature on White vs Black NFL players, in which White athletes are diagnosed more frequently with postconcussion "dementia" and receive greater compensation for this disability. More importantly, Dr. Roberts emphasizes that this racial discrepancy in dementia diagnoses is not likely an indicator of differential disease burden between races but is more reflective of racial care inequality. Dr. Kornblith agrees that racial disparities in health care are ubiquitous and demand more than just our attention. They demand action.

James E. Siegler, MD, and Steven Galetta, MD

Neurology ${ }^{\circledR}$ 2021;97:150. doi:10.1212/WNL.0000000000012284

\section{Reader Response: Sex, Race, and Risk of Dementia Diagnosis After Traumatic Brain Injury Among Older Veterans}

Jomar S. Roberts I (Matthews, NC)

Neurology ${ }^{\circledR} 2021 ; 97: 150$. doi:10.1212/WNL.0000000000012288

I read the article by Kornblith et al. with interest. ${ }^{1}$ It seems this "trend" in diagnostic bias is not exclusive to veterans alone. As this article is being published, Black NFL and former NFL athletes are involved in litigation regarding the discrepancy in qualifying postconcussion dementia diagnoses applied to White athletes vs Black. White athletes are diagnosed with postconcussion dementia at higher rates and are thereby compensated for this at higher rates than Black athletes. ${ }^{2}$

In my experience as a veteran TBI neurologist, observing this bias is commonplace and not limited to concussion or any particular disease. The health care system is riddled with bias from the provider level on down. It manifests openly in less care being given to Black patients, less concern being given to their disease, and less resources allocated to deep diving into their illnesses. This is not a secret to Black neurologists or providers in any field and is openly discussed and hard fought against, daily.

To be perfectly honest, these authors are speaking softly about an issue that needs to be addressed much more openly. Racial bias in health care provision starts at the individual provider level. We need to further examine how providers' backgrounds affect their patterns of diagnosis, test ordering, and prescribing patterns. This should be prominently displayed in some metric for all patients to use when choosing a provider, a "bias report card" so to speak. Only with full transparency will patients be given the assurance their doctor/provider is giving full, ethically unbiased care to all.

1. Kornblith E, Peltz CB, Xia F, et al. Sex, race, and risk of dementia diagnosis after traumatic brain injury among older veterans. Neurology. 2020;95(13):e1768-e1775.

2. Radnofsky L, Beaton A. Lawsuit alleges NFL's concussion settlement discriminates against black players. In: The Wall Street Journal. Available at: wsj.com/articles/lawsuit-alleges-nfls-concussion-settlement-discriminates-against-black-players-11598371843. 


\section{Author Response: Sex, Race, and Risk of Dementia Diagnosis After Traumatic Brain Injury Among Older Veterans}

Erica S. Kornblith (San Francisco)

Neurology ${ }^{\circledR}$ 2021;97:151. doi:10.1212/WNL.0000000000012286

Thank you for the thoughtful comment on our article, ${ }^{1}$ Dr. Roberts. We agree that racial bias in health care is pervasive and must be addressed. We hope that our work draws attention to this issue and highlights the need for research aimed at identifying and mitigating disparities.

1. Kornblith E, Peltz CB, Xia F, et al. Sex, race, and risk of dementia diagnosis after traumatic brain injury among older veterans. Neurology. 2020;95(13):e1768-e1775.

Copyright @ 2021 American Academy of Neurology

\section{CORRECTIONS}

\section{Thrombolysis in Acute Ischemic Stroke in Patients With Dementia}

A Swedish Registry Study

Neurology ${ }^{\circledR}$ 2021;97:151. doi:10.1212/WNL.0000000000010325

In the article "Thrombolysis in Acute Ischemic Stroke in Patients With Dementia: A Swedish Registry Study" by Zupanic et al., ${ }^{1}$ the affiliations for Drs. Zupanic and Kramberger should include "Faculty of Medicine, University of Ljubljana, Slovenia." The authors regret the error.

\section{Reference}

1. Zupanic E, von Euler M, Kåreholt I, et al. Thrombolysis in acute ischemic stroke in patients with dementia: a Swedish registry study. Neurology. 2017;89(18):1860-1868.

\section{ALS is a Multistep Process in South Korean, Japanese, and Australian Patients}

Neurology ${ }^{\circledR}$ 2021;97:151. doi:10.1212/WNL.0000000000010323

In the infographic corresponding with the article "ALS is a Multistep Process in South Korean, Japanese, and Australian Patients" by Vucic et al., ${ }^{1}$ the labels for the pictures of South Korea and Japan should be switched so that South Korea reads as a 5-step process and Japan reads as a 6-step process. The editorial team regrets the error.

\section{Reference}

1. Vucic S, Higashihara M, Sobue G, et al. ALS is a multistep process in South Korean, Japanese, and Australian patients. Neurology. 2020; 94(15):e1657-e1663. 